\title{
Field anthropological research for context-effective risk analysis science in traditional cultures: the case of Senegal
}

\author{
Chiara Frazzoli ${ }^{1}$ \\ 1 Department of Cardiovascular and Endocrine-Metabolic Diseases, and Ageing, Istituto Superiore di Sanità, Rome, Italy \\ Keywords: senegal, ecology, toxicology, malnutrition, prevention, sub-sahara africa \\ https://doi.org/10.29392/001c.12922
}

\section{Journal of Global Health Reports}

Vol. 4, 2020

\begin{abstract}
Background
Nutritional homeostasis and health are increasingly affected by rapid nutrition transition, rapidly changing (food producing) environments and lifestyles, and increasing global formal and informal markets of consumer products. Toxicological risk factors are currently poorly focused in sub-Sahara Africa. Whereas important differences exist amongst countries, Senegal exemplifies the general trend. Focusing on Senegal, this work aims to build a translational framework for context-effective risk analysis science in traditional cultures by i) highlighting main aspects of eating and producing, with focus on savannah areas and pastoral systems, and analyzing their impact on socio-economic development, ii) analyzing people's preparedness and proactivity, as well as channels and tools for prevention, and iii) discussing reasons of widespread demand of external education on diet and healthy foods.
\end{abstract}

\section{Methods}

Participant observation in field anthropological research focused on food culture, consumer products and food systems in urban, semi-urban and rural settings. The system was stimulated with seminal messages on toxicological risk factors for healthy pregnancy and progeny's healthy adulthood disseminated in counselling centres and women's associations.

\section{Results}

Communities were unprepared against rapidly increasing exposure to toxicological risk factors but proactive (eg, midwifes) towards empowerment on healthy habits and good practices. Anthropological and ecological approaches can leverage the risk analysis science by working with identified enablers and barriers, channels and tools, traditional diet and local food chains. External efforts for local socio-economic development may have been limited so far by poor understanding of pastoral cultural roots.

\section{Conclusions}

With the globalization of culture and products, the mechanisms underlying the developmental origin of health and diseases at individual level correspond to a new strategy at population level that requires a decrease in childbirth and aspiration to next generation's better health and healthy life expectancy. This biocultural adaptation offers Africa the framework for focusing on the prevention of new (transgenerational) health risk factors and recovering local food chains and culture, and requires global ethics and advocacy in the global formal and informal markets.

Increasing numbers of literatures infer that urbanization and associated nutrition transition towards western dietary model and food fashions (eg, "fast food" representing the modern economy and lifestyle) make people more subject to chronic diseases than those who eat traditionally. ${ }^{1,2}$ With the commodification of land and labour in the pastoral sector and the rapid transition to an urban economy and lifestyle, malnutrition is not only a problem of emergency (eg, famine or contaminated breast milk, see eg, ${ }^{3,4}$ ), but al- so a problem of socio-economic development: malnutrition covers environmental health, primary food productions' safety and dietary habits. Toxicological risk factors for communicable and non-communicable diseases (NCDs, eg, diabetes, obesity, hypertension, cardiovascular disorders, cancer) and their comorbidities are emerging in economically developing countries. ${ }^{5}$ According to the International Academy of ecology and environmental science, ${ }^{6}$ the outbreak of NCDs in economically developing countries is related to 
the rising environmental pollution (eg, pesticides, toxic elements). The burden of communicable diseases (eg, malaria, kwashiorkor, HIV/AIDS) is also investigated in terms of toxicological risk factors. ${ }^{7-9}$

In particular, organism development (eg, programming of reproductive, neurological, metabolict, musculoskeletal and cardiovascular systems and immune function, or maturation of organs and tissues) during intrauterine life and first infancy are critical/most sensitive windows during which stressors can alter gene expression and increase the susceptibility to "second hits" during childhood, adolescence or adulthood. Adverse effects may persist until at least the third generation (transgenerational predisposition, from grandmother to grandson). ${ }^{10}$ In particular, maternal diet is a priority issue in mother-to-child health (or transgenerational health) as it implies the conceptus nutrition and toxic exposure, ie, progeny's health challenges of healthy adulthood. ${ }^{5,11}$ Among maternal exposure sources, food safety and balanced diet contribute so prominently that the ONU concept of "sustainability" 12 has been applied to health. Sustainable Food Safety (SFS), conceptually developed in a previous work, ${ }^{5}$ can be defined here as a form of negotiation between current and next generation, ie, "the complex of actions intended to minimize adverse health impact on future generation associated to today's safety of food and nutritional quality of diet".

Among toxicants, endocrine disrupting chemicals (EDCs) (eg, some groups of plasticizers and pesticides) represent the main concern for developmentally-induced NCDs. With globalization of culture and products, toxicological hazards, including EDCs, are new risk factors for health in Africa, and countries and people are unprepared to face them. In these fast-changing environments, rapid nutrition transition, rapid changing (food producing) environments and lifestyle, and the increasing global formal and informal markets of consumer products require risk analysis-driven bottom up activities in combination with risk analysis-driven top-down actions against toxicological risk factors. ${ }^{13}$ The African scientific community is growing interests on the issue $\left(\mathrm{eg},{ }^{14}\right)$.

The present work approaches a framework for diseases prevention where cultural and ecological features are blended in the design of a context-effective risk analysis science in Africa. Translational aspects of the science of toxicological risk analysis in traditional cultures require anthropological comprehension of diet and consumption preferences as well as ecological understanding of food systems, awareness and empowerment to i) clarify the causes and dynamics of human health and diseases, diets, lifestyles and behaviours, ${ }^{15}$ ii) define the basis for the 4 steps (hazards identification, risk assessment, risk management, and risk communication) of risk analysis (eg, $\left.{ }^{16}\right)$, and iii) handle uncertainties and data gaps in data poor countries. ${ }^{17}$ In particular, this work aims to i) highlight main aspects in the anthropology and ecology of eating and producing, with a focus on savannah areas and pastoral systems, and analyze its impact on development, ii) analyse people preparedness to toxicological risk factors, and understand the deep reasons of the widespread local demand of external education on diet and healthy foods, iii) analyze feedback and pro-activity after targeted stimulation on the field.
The work focused on Senegal as one of the first African countries living nutrition transition. ${ }^{2,18-20}$ While malnutrition and micronutrient deficiencies are not eradicated, Senegal presents an increased prevalence of severe diseases related to an excessive and unbalanced consumption of foods and calories such as obesity, hypertension, diabetes, hypercholesterolemia and cardiovascular disorders.

\section{METHODS}

Participant observation in field anthropological research focused on food culture, consumer products and food systems in urban, semi-urban and rural settings in order to attain a comprehensive understanding. Field investigation, partly referred to as "consumer safari", ${ }^{21}$ consisted of one month (February 2010) spent with consumers in their homes in the different settings (Box 1).

\section{Box 1. Consumer safari}

The consumer safari was intended to:

- collect information on Senegalese food culture, diet and meals,

- collect information on feeding practices for new-born and infants,

- analyse roots of Senegalese food culture and productions, eg, the pastoral system,

- collect information on food systems and dairy production,

- analyze the ecological nature of Senegalese food and diet, and assess its impacts on development,

- understand how people, especially mothers, use food-related and consumer products,

- extrapolate context-specific prevention activities in Sustainable Food Safety,

- analyse reasons for the widespread local demand of external education on diet and healthy foods.

The field research interested the regions of Dakar, Thiès and Diourbel. Dakar is the capital city of Senegal, located on the Cap-Vert Peninsula, on the country's Atlantic coast. It is Senegal's largest city. Its position is an advantageous departure point for trans-Atlantic and European trade. Over 10 million people live in the country, of which more than 2 million live in Dakar, the rest in other cities, particularly in central and southern zones of Senegal. Mbacké is a town in central Senegal, located $190 \mathrm{~km}$ east of Dakar. It is the capital of an administrative department in the Diourbel region. Along with the near-by city of Touba, Mbacké forms an urban conurbation which population makes it Senegal's second largest agglomeration, after the capital region of Dakar. The Department of Mbacké includes Mouride Islamic Sufi order's holy city of Touba that hosts the largest annual Is- 
lamic pilgrimage in the country (Grand Magal).

This conurbation area is a polycentric urban agglomeration, in which transportation has developed to link areas to create a single urban labour market or travel to work area. Senegal has one of the highest urbanisation rates in West Africa: according to the UN Human Settlements Programme, $48 \%$ of the population lives in urban areas and the slum to urban population ratio is $76 \%$. Where urbanization has increased suburbs of metropolitan areas or connected adjacent metropolitan areas in conurbation areas, infrastructures are likely not suited for large populations, so there are issues related to pollution, disposal of waste, not to mention the stress associated with noise and effects of increasing population density. This is particularly true for Touba.

To understand better the Senegalese food chains, rural villages of nomadic Fulani (in particular those in the Thiès region) were also visited. The Fulani (also known as Fulbe or Peuls) are among the most widely dispersed and culturally diverse people in Africa. Many Fulani trace their beginnings back one thousand years to the Senegambia area; nomadic, pastoral Fulani (full-time cattle keepers) are called Mbororo'en, whereas the settled Fulani are called Fulbe wuro. The Mbororo'en moves about with their cattle for most of the year.

The Casamance region in southern Senegal is the wettest part of Senegal, with high rainfall promoting the growth of forests. Casamance is largely separated from the rest of the country by The Gambia and was not visited. Moreover, Casamance is also particularly vulnerable due to longestrunning civil conflict.

Information collected on the field have been validated and integrated by Senegalese cooking recipes detailed by the organization DEGGÒ of Senegalese women immigrated in Italy, and available scientific literature.

\section{SYSTEM STIMULATION}

The system was stimulated with seminal messages on toxicological risk factors for healthy pregnancy and progeny's healthy adulthood in order to: i) analyze feedback and proactivity, and ii) identify channels and tools for widespread and effective prevention of risk factors.

When necessary, dialogues, in English or Italian languages, were translated in Wolof by members of the Italian Senegalese association of women and, in the second phase, by members of the Senegalese association of Midwifes.

Figure 1 shows the life-cycle illustration cards used to circulate key seminal messages in counselling centres, groups of citizens, association of women. As detailed in the Results sections, the same cards were used in subsequent meetings with the proactive association of midwifes. Essentially, the following aspects were discussed. Health is a transgenerational capital through the diet and the environment (pre-, peri- and post- gestational maternal nutritional status and toxic body burden transmitted primarily via placenta and breastmilk). Apart the multifaceted range of genetic susceptibility within the population, micronutrient deficiencies may be elicited by suboptimal intake, metabolic interference by anti-nutritional factors and contaminants (eg, arsenic, cadmium, tin, mycotoxins), or by deficiency or excess of other micronutrients. Micronutrient deficiencies in the foetus can also happen under apparent appropriate nutritional status of the mother and result in adverse pregnancy outcomes (eg, foetal loss, intrauterine growth restriction, preterm birth, birth defects). A well-known example of preventive effect of an adequate micronutrient intake is vitamin folic acid against neural tube defects (NTDs). In general, a diet rich in fruits, eggs and especially green vegetables gives the woman sufficient folic acid and protective nutrients (eg, zinc, inositol) if it is taken as a habit before the start of pregnancy, because NTDs and other congenital malformations are induced very early in gestation. A wrong or inadequate stimulus in utero or in the early neonatal life stages (eg, mycotoxins, dioxins, pesticides, plasticizers) may also enhance the risk of developing metabolic disorders and non-communicable diseases later in life. Micronutrient deficiencies facilitate paediatric susceptibility to infections and weaken the immune responses; in their turn, infections aggravate micronutrient deficiencies both by reducing nutrient intake (decreased strength and appetite, increased diarrhoea) and by interfering with their metabolism. Immunotoxicants (eg, mycotoxins, aluminium) can directly impair the immune function. ${ }^{8}$ Early and exclusive breastfeeding for 6 months provides the appropriate amounts of nutrients for adequate development (eg, iodine for thyroid function, body growth and intellectual development; long chain polyunsaturated fatty acids for maturation of immune system), antiviral, antiparasitic and antibacterial activity for gastro intestinal maturation, and reduces deaths caused by diarrhoea, asthma and pneumonia.

\section{RESULTS}

\section{EATING IN SENEGAL}

Between sub-Saharan food culture, Senegalese cuisine has special features distinguishing the wealth of recipes and taste, probably also linked to the geographic location of the territory of Senegal at the crossroads of cultures (sub-Saharan Arab culture, Guinean black culture) and tastes (sea and inland, savannah).

Food traditions include two aspects: foods and how they are eaten. A food is more than the sum of its nutrients and a diet is more than the sum of its foods. It is also true that a food culture is more than the sum of its recipes. A food culture includes the collection of costumes, dietary habits and tacit rules that govern the relationship of people with food and eating. Eating is a main component of social life in Senegal and, even some restaurants along main streets serve travellers, food is preferably cooked at home to be eaten with friends and relatives. Besides snacks, street cooked food is not marketed except in some districts of the suburbs of Dakar. Sugary drinks and snacks are available in most rural villages of Senegal.

In collective societies such as Senegalese villages, food, analogously to lifestyle, is collective. Meals are consumed in a single flat dish on the ground, the guests sit down on the floor or on small stools and eat using the right hand or the spoon. Residual food is never recycled or stored but soon offered to poorer families or fortuitous visitors. The issue of hazardous contamination of food is often out of control and 


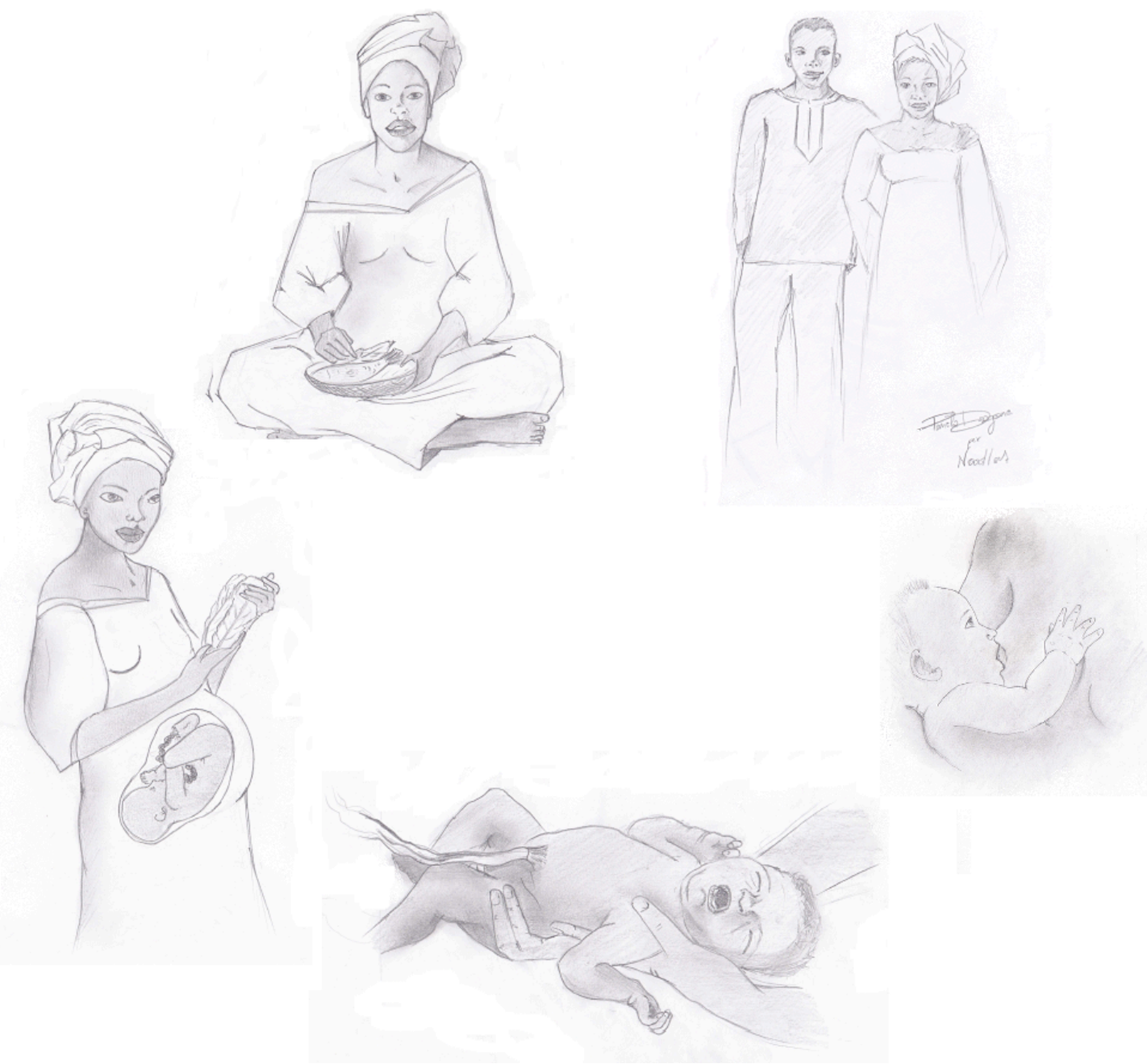

Figure 1. Life-cycle illustration cards

Illustration cards show phases (mother in childbearing age, intrauterine life, breastfeeding) in mother-child health flow in which toxic exposure is especially critical to the chance of healthy birth and healthy adulthood (๔ NOODLES NGO)

ignored.

\section{SENEGALESE DIET}

In Senegal diet and food are traditional, and almost reproducible in the semi-arid region of Senegal. ${ }^{22}$ Traditional daily diet is not deficient in calories and proteins; however, especially in rural areas and in the poorest areas of cities, is less varied, and possibly less rich in essential nutrients, than it would seem at first glance.

Fish is mainly consumed dried and, even though diffused, is considered as a "food for the poor"; only two or three meals are cooked with palm oil; peanut oil is the widespread vegetable fat for cooking.

Previously unknown highly processed foods -high in salt, fats and sugars- are replacing traditional foods and ingredients; one example is the widespread diffusion in West Africa of flavor enhancers (based on glutamate) mainly due to low price, conservation that does not require refrigeration, and 'modern' fashion. The massive market of seasonings has rapidly introduced in the traditional diet significant amounts of sodium chloride and sodium glutamate (possibly playing as risk factors for the syndromes of hypertension). Exposure to glutamate-based additives may exceed the acceptable levels and cause concerns for neurological effects. ${ }^{23}$ The Senegalese consumer frequently perceive glutamate-based products as healthier than traditional ingredients such as sumbalà (natural extract of the neré plant) or dried fish; in addition, new flavours and new tastes are essential components of eating pleasure and can also increase the amount of food consumed. Currently, many campaigns on social media face the use of broths and invite the population to use natural spices.

Further to the regional ones, all dishes have many variations: the ceeb ü yapp may also be red, the ceebü ginaar also white, the cü can be prepared with meat, shrimp or bülett (fish balls). The precious coff in the ceebü jén can be replaced with less expensive fish (eg, the yaboy, Sardinella aurita); the use of vegetables can be limited or, away from the sea, simple dishes of millet and tapioca (manioc starch) are prepared.

Noticeably, fruit is not part of the traditional meal; moreover, it is relatively expensive and especially consumed as canned juice. Raw foods (fruit, raw vegetables, fresh 
juices and centrifuged of fruit and vegetables) are poorly consumed. The benefits and protective effect of eating fresh fruit and vegetables are poorly known.

\section{SENEGALESE MEALS}

Ndékki li (breakfast). For breakfast, people eat mainly bread (French baguette) accompanied by tuna (Pinton, a sardine paté produced in Dakar), imported cheese (eg, mozzarella and groviera), mayonnaise (in the traditional version or white, made by Fulani with milk and without eggs) or imported margarine and Senegalese chocolate. These foods are available in any boutique (small shop, equivalent to Italian grocery store of several years ago), at least in cities. Also sandwiches with gruyère, beef saucisson or omelette and, since a few years back, jams of Senegalese production are consumed.

$A \tilde{n} b i$ (lunch). Lunch is the main meal and for many Senegalese is equivalent to ceebu jén (rice with fish) with the variance of colour (white or red); the ceebu jaga is like ceebu jén but accompanied by a sauce of fish balls and vegetables quenelles. Alternatively, rice is prepared with meat, as the ceebu yapp (rice with lamb), the ceebu ginaar (rice with chicken) and the ceebü Géjii (rice with dried fish and beans). Yét (dry mollusc, it is a large sea snails), tamba jén (small dried fish flavour similar to that of anchovy), tufa (small dry molluscs) and/or pañ (clams) are often in the recipes. The following meals, called ñaari cin, are prepared in two pots, one for the sauce (meat or fish and vegetables) and the other for white rice (nancata $\eta$ ): mafe and domoda (beef or lamb), yassa jén (mullets), yassa ginaar (chicken), cu jén (mullets or sea bream), cu diw tiirr (grouper), suppokanja (mullet or grouper, paw of beef, shrimp), curry (lamb). The rice brisé, whose grains appear very small because they are broken, is the best for ceebu jén.

Reer bi (dinner). Lighter and more various dishes are served for dinner: meat, chicken or fish and salads, firir (mullet or sea bream), bulett (grouper fish balls) to eat with bread, risotto-like rice (ceebu toy, such as the daxinn, the mbaxall or the ceebu tatu naar), couscous or pasta (spaghetti or small macaroni) with meat and onions sauce, the supp of ox or mutton legs and the traditional cérè, ie, Senegalese couscous made from millet that is consumed with a sauce of meat and vegetables or served as a basis for the preparation of desserts. Géjii (dried fish), yét (dry mollusc, it is a large sea snails), tamba jén (small dried fish flavour similar to that of anchovy), tufa (small dry molluscs) and/or pañ (clams) are often in the recipes. The local fast-food serve hamburgers, chawarma (Arab bread filled with meat cooked on the spit, onions, tomatoes and fried chips) or pizza; in the dibiteries you can buy beef or lamb meat just grilled and served with mustard, chilli and raw onions.

Leccantu (snacks). Peanuts grills in the sand, salted or with sugar (gerte caff o gerte xott o gerte sucar), cashews from the Casamance, fataya and pastel (respectively filled with meat and fish) or akra (beans croquette) with spicy sauce, beñé (sweet), green mango with a little salt or the cerises (small green and bitter fruits), tandarm (fresh or dried dates, especially consumed during Ramadan), mboqq (toasted corn cobs) are consumed as snacks.

Sweets. Sweets can replace dinner or breakfast, for ex- ample the lax (grain millet with raisins, yogurt or sow, ie, curdled milk, and sweetened condensed milk) or the ngallax (grain millet, baobab fruit and peanut paste) are served during particular periods (eg, the caakry on nights of Ramadan).

Soft drinks. "Potable" water in sold in bags. The term "boisson" means all American sodas or their Senegalese version, which are sold in all the boutiques. Local drinks are named "jus" (juice), the most famous is the ice served bissap (infusion of red flowers of Hibiscus sabdariffa similar to karkadé), but also daqqar (tamarindo, tamarindus indica), ginger (slightly spicy taste), ditax juice (Detarium senegalense, the buyy (Baobab fruit) and cocktails. Most popular drinks are the duté infusion (Combretum micranthum), milk powder and soluble coffee; children add cacao powder to milk; very few use UHT milk. The Touba coffee contains jarr (Syzygium aromaticum, a slightly pepper flavoured spice). The meal ends with ataya that is the set of three tea, one strong and bitter (the lëwëI), one sweetened and one mint-flavoured.

\section{FEEDING PRACTICES FOR NEW-BORN AND INFANTS}

Programmes in Senegal discourage early introduction of formula and/or solid, semi-solid or soft foods to infants aged 3 to 5 months and promote exclusive breastfeeding. ${ }^{24}$ In Senegal, approximatively, $56 \%$ are practising exclusive breastfeeding for 6 months. ${ }^{25,26}$ Breastfeeding is widespread and duration ranges from 12 to 36 months, with an average of 18-24 months. In particular, an average duration of 18 months is observed in Dakar compared with 24.3 months in rural areas. Early and exclusive breastfeeding is generally a highly recommendable health-promoting practice that needs further support in Senegal where, eg, feeding water is still a common practice and neonates are not fed colostrums regularly. Throwing away colostrum, the highly nutritious first breastmilk, is a common practice in Senegal. Many mothers gave their infants water to drink in addition to their breastmilk and infant formulae, thus exposing their babies to many possible waterborne diseases, like diarrhoea and acute respiratory infection, ${ }^{27}$ and contaminants impacting nutrition (wasting and stunting) and toxic body burden. Watery millet gruel (or millet or rice) is given in response to perceived breast-milk insufficiency. ${ }^{28}$

\section{DIETARY ROOTS IN SENEGALESE SAVANNAH: THE PASTORAL SYSTEM}

Nomadic pastoral Fulani (Mbororo'en) live in small, temporary camps that can be quickly dismantled as they move in search of pasture and water for their herds. In rural areas, kin groups (Lenyol) tend to live close together and join in work efforts, whereas in towns and cities they tend to widely disperse. The primary goal of pastoral production is subsistence security in the short and long term. This is largely achieved through accumulation of animals, species diversification and maintenance of social ties. Seasonal and annual fluctuations in food supply are coped by hunting wildlife and, where possible, agricultural foodstuffs (obtained by trade or minimal cultivation). ${ }^{29}$ Further to the need of secure markets to sell animals and purchase foods, the pas- 
toral Fulani are currently facing many problems: i) drought that often reduces water supply and pasture, as well as impairing herd's health; ii) increasingly less land available for herding and iii) increased conflicts with settled people. Present-day governments are also curtailing the Fulani movements or trying to force them to settle down. To respond to adverse socio-economic and environmental conditions, pastoralists in the Senegalese area of Ferlo are reinventing their livelihoods by increasing their involvement in the national market economy in order to continue a "pastoral way of life". 30,31

\section{PASTORAL ROOTED CULTURE AND TODAY DAIRY PRODUCTIONS}

In general, lactase production in the small intestine is high and vital during infancy, but it begins declining at the ages of 2 years, around weaning; most adults retain only about $10 \%$ of infant lactase activity, presenting lactose malabsorption or intolerance. Since lactase is a substrate-inducible enzyme, the regular consumption of milk lets lactase persist in adulthood. The adult ability of digesting lactose in milk, or lactase persistence, has developed under particular ecological (environmental and dietary subsistence) conditions, and is clearly explained by the culture and genetic evolution hypothesis. ${ }^{32,33}$ Lactose tolerance is an evidence of the Senegalese pastoral rooted culture. Noteworthy, a method of biotic adaptation to aridity is extracting protein from otherwise unpalatable cellulose of grasses and shrubs through the secondary use of the products (milk) of domestic ruminants. ${ }^{34}$ In Senegal, further to the Fulani people that show full tolerance, only $29 \%$ of the population has lactose malabsorption. ${ }^{35}$ Long-term survival of societies living in savannah areas is secured by valuable and respected traditions; it has been questioned if these may be defined real poverty or rather the sole way of life and sustainable habitation in highly arid environments. ${ }^{36}$

The Senegal beef capital was estimated in 2019 to approximately 3 million cattle, which produce a quantity of milk equal to 130 million litres/year (7 litres in the rainy season and 3 in the dry season). The main breeds are the Zebu Gobra, at the North and the Centre Sahel area of the country, and the N'Dama that, because of its tripanotolerance, has colonized the southern areas. Where the two breeds coexist, the Djakoré has developed. Besides bovine milk, there is also some production of goat and ewe milk, but it has a minor role.

Despite attempts to answer with local production to the increasing demand for dairy products, Senegal must import approximately two thirds of the milk needed, both as milk powder and finished products. Local milk is sold both raw and transformed sour curdled milk (lait caillé), yoghurt, and regenerated milk. Milk powder is a raw material, sold under numerous brands, used in vast numbers of products (eg, thiacry, ie, yoghurt and cereals, fondé ie, millet with yoghurt, and sombi ie, rice milk) and in different forms of packaging (eg, bags, jars, plastic bottles) by countless companies at various levels (handcraft, small transformation industries up to multinationals).

In the area of extensive pastoral system in the northern pastoral area (Ferlo) and at the Senegal River, farming is characterized by a periodic movement of the herds from the internal area of the Ferlo (Diéri) and the flood region (Walo). The pastoral zone is the only presenting milk production surpluses, but the lack of processing units and their remoteness from large roads and centres of consumption penalize its economic potential. The serious problems related to the system of collection (by foot, bicycle or car, sometimes even over long distances) as well as to the lack of the cold chain increases the number of associations for processing local milk; some of them benefit government support, as in the peanuts area (administrative regions of Diourbel, Louga, Kaolack, Fatick and Thiès). Here, the agropastoral system integrates agriculture and breeding, and livestock is intended as investment, savings and workload; peanuts and by-products are used to feed livestock. Also in the South of the country (administrative regions of Tambacounda and Kolda, Ziguinchor) crops of peanuts, rice, cotton and sesame seed integrate N'Dama breeding.

Around the major urban centres (Dakar) the intensive system is developing to meet the increasing demand for local product; noteworthy, the ferme de Niacoulrab and the ferme de Wayembam born from private initiatives. In intensive rearing, with predominantly foreign breeds of European origin such as the Jersiaise, Montbéliarde and Frisone (all local names), artificial insemination with imported semen and mechanised milking have been developed; here, milk surplus becomes caillé only in more favourable seasons.

The price of fresh milk is variable; in large urban markets, price fluctuated between the 450 and 700CFA per litre, which makes it expensive and a poorly competitive food. Cheese is generally imported from Europe: to date, both dietary habits and cost make it a niche product.

Even in pastoral communities, in sub-Sahara Africa cheese is primarily only a method for storing milk surplus during the rainy season. Although cheese making technologies can be useful and beneficial, its spread in rural areas and traditional habits is limited in the sub-Sahara, except urban settings and commercial enterprises (companies, cooperatives, etc). Nevertheless, there are examples of cheese-making tradition: the Fulani in northern Togo and Benin and neighbouring Nigeria have a habit of producing the waragashi.

Further to cultural and environmental (temperature) factors, some anthropological reasons may clarify the limited cheese-making tradition (often limited to yogurt) in subSaharan Africa. The presence of calcium in milk does not guarantee by itself the full calcium absorption: lactose (4-5\% in unprocessed animal milk) facilitates (up to $78 \%$ ) calcium absorption in the intestine. ${ }^{37}$ Lactose is a watersoluble molecule: after the curdling (coagulating) process, it remains in the water portion but not in the fat portion. During milk acidification, lactose is "self-digested", ie, fermented, by spontaneous milk microflora (Lactobacillus) into lactic acid; the degree of the process depends upon temperature and duration of the incubation. Fermentation, high fat content milk, aging methods of hard cheese and soft ripened cheeses reduce the lactose content. Lactose will still be present in lesser quantities in curds, butter and yogurt. Thus, fermented milk, yogurt and cheese means de- 
creasing the possibility of using lactose to facilitate calcium absorption. Noteworthy, also vitamin $\mathrm{D}_{3}$, or cholecalciferol, is critical for calcium absorption in the body; this vitamin derives from a particular form of cholesterol in epidermis that is converted by ultraviolet (UV) radiation penetrating the skin. Populations living in sun-intensive regions, where the amount of UV radiation penetrating the skin is minimised by dark skin melanin (protective action against skin cancer), have therefore minimised the production of vitamin $D_{3}$ and, hence, calcium absorption. Under this condition, the advantage of intake of lactose through milk is high and the utility and convenience of producing cheese decays: in these lands, fresh and powdered milk are processed up to lail caillé and yogurt, not more.

\section{EFFECTS OF PASTORAL ROOTS ON DIET AND SOCIO- ECONOMIC DEVELOPMENT}

One reason for the limited variety of dishes in Senegal may lie in the absence of food recycling.

One can think that both climate (over $30^{\circ} \mathrm{C}$ almost all the year) and daily availability of food in pastoral communities do matter and that the food recycling practice has arisen in farming cultures that need to optimize resources and save foods for the winter; this cultural framework defines its values in terms of economising behaviours. On the other side, in the pastoral culture the relative abundance (availability of food, dressing and housing) decreases the need of socio-economic development, and storing and recycling have less reason to exist. Thus, in a "pastoral roots" view of the "quality of life", the food surplus from the meal is not recycled nor saved; it is offered to poorer families or to visitors (who may be migrants, pilgrims, sellers, or even people passing-by). Thus, food offering is part of a series of actions that maintain the social links; visiting and sitting around food or beverages are all-important activities in the Senegalese everyday life.

The traditional framework of day-to-day social relations may find its markers in scantily furnished houses and time for exchanges of visits, when greetings, invocations, protections and blessings last for minutes. In this context, only the understanding of values and goals of pastoral rooted production and viewpoint on life will allow to suggest more appropriate and feasible prevention initiatives. Pastoral social organisation is the basis of the traditional social security functions and stability of the entire community. This behaviour receives further support by the bonds and customs created by the Islamic community, which in Senegal is characterised by the influence of the Mouride brotherhood.

Another component is the agricultural structure of Senegal, which pivots on the peanut farming. Monocultural farming, basically linked to the production cycle of a single plant species, is less able to foster a varied side-production accompanied by timely rotation of cultures and food storage. In a country where plantations of peanuts cover $40 \%$ of the cultivated lands, the subsistence farming that produces millet, cassava and rice does not receive adequate support and the country is forced to import staple foods. For instance, since the end of the $19^{\text {th }}$ century, when the French colonialists imposed rice from their settlements in Indochina, rice is often imported from Asia because local produc- tion does not cover national requirements. However, there are currently many government projects promoting the cultivation of local rice and short cycle species in some areas.

\section{REASONS FOR THE WIDESPREAD LOCAL DEMAND OF EXTERNAL EDUCATION ON DIET AND HEALTHY FOODS}

Africa is a large reserve of food that local communities have always used sustainably, by remarkable understanding of the territory and unique expertise in sustainable use its resources. ${ }^{29}$ Traditional food culture has been selected by the territory. ${ }^{38}$ Food and dietary traditions reflect a millenary experience and often express a nutritional logic, ie, the best way to merge human needs with the available resources in that place. ${ }^{39}$ Systematic analysis of scientific «evidence» by public-health experts has already proved to converge with diets and lifestyles evolved by all the populations worldwide after millennia. ${ }^{40}$ Based on these assumptions, and pointing at properly interpreting the needs of millenary African communities, field participant observation investigated why many traditional communities have lost their dietary know-how, why these communities should need external education on how to manage the foods their soil produces. The current malnutrition and the need for training on basic nutritional and safety notions ${ }^{41,42}$ appear anomalous in the general criteria of selection.

It is true that the access to nutritional variety has been limited in those traditional villages whose agricultural shapes have been deleted by monocultures and productions of goods (often not foods) for exportation. African historians explain the poor proactivity with structural long-lasting deconstruction of African dynamics.

It is also true that a new living environment with new products brings about new chemical exposures (plasticizers, preservatives, biocides, flame retardants, heavy metals, pesticides) from eg, intensive food productions, food transformation and consumer products. ${ }^{5}$ The onset of an obesogenic environment with higher availability, accessibility and affordability of junk food and new low-quality or hazardous products from the increased and increasing globalized market can be very fast. Rapid import of lifestyles (eg, sedentary life, altered timing/frequency of meals and sleep, energy-dense diet, less consumption of dietary fibers and water, smoking habits and social consumption of alcohol, fast food and imported food) associated with unawareness can result in i) exposure to new (environmental, dietary, consumer products) toxicological risk factors, and ii) diminished ability of the body to restore a functional internal environment, with consequent body burden of toxicants that might exceed the body protective detoxification rate. An interesting point is that a deeper cultural change occurred in several African populations, including the Senegalese one, ie, the change in population's survival strategy that requires increase in infants' survival and in healthy adulthood chances. The millenary population's survival strategy in Africa has been the early first birth, the high number of deliveries and large families: the high number of children balanced the huge infant mortality and the low life expectancy. On average, women have five children but the population dynamics is changing. Currently, in Senegal, child mortality is not yet low (6\%) but is falling rapidly; fe- 
male education remains low, but family-size is decreasing quite rapidly as a form of biocultural adaptation.

The driving force behind these changes appears to be the trend towards later marriage and later first birth and desire to have fewer children. ${ }^{43-45}$ Indeed, the decrease in childbirth and the new population survival strategy require increase in infants' survival and aspiration to next generation's better health and healthy life expectancy. ${ }^{46}$ The changing in demographic dynamics, urbanization, and women' roles as well as westernization of dietary preferences and habits are correlated social phenomena. ${ }^{47}$

The food culture must adapt rapidly and, under the described conditions, the management of the fast-changing living environment (including foods and food chains) and related toxicological risks pose special challenges related to food safety, food diversification (nutrition security) and SFS. Maternal investment in offspring in prenatal or early postnatal life have profound implications for the evolutionary fitness of offspring. ${ }^{48}$ These considerations at population level reflect biological evidence of what happen at individual level, ${ }^{49}$ ie, how rapid improvement in nutrition in the early life respect to the in utero life and other factors (eg, toxic exposure) may impair organism development and increase susceptibility to disease. ${ }^{50,51}$

With rapid globalization of culture and products, traditional communities are not only unprepared in aspects of infrastructures, laws, regulations, but also in information and awareness. Preparedness means that communities need education and empowerment to prevent risky behaviors and protect from todays' toxic exposure the chance of healthy adulthood and healthy life expectancy of their progeny.

\section{CHANNELS AND TOOLS FOR CONTEXT-EFFECTIVE RISK ANALYSIS}

Risk analysis-based approaches can generate i) useful information at individual, household and community level and ii) awareness on practices preventing or mitigating hazards on public health issues ranging from consumer products (eg, BPA baby bottles), ${ }^{52}$ food handling and cooking, 8,53 traditional nutraceutical (eg, geophagic clays) ${ }^{16}$ and the environment (eg, e-waste). ${ }^{4}$ Also in data poor context (like Africa) the available scientific evidence worldwide allows risk assessment and uncertainties handling. ${ }^{17}$ For instance, good practices in the kitchen can exploit the nutritional value of staple foods and traditional recipes through the mitigation of dietary toxic exposure..$^{8,53}$ In kitchen toxicology, the steps of the recipe (from purchase of raw ingredients through to food handling, cooking, storage, and consumption) are examined by focusing on specific toxicants and anti-nutritional factors to identify those steps presenting feasible options for risk management. ${ }^{8,53,54}$ Cultural barriers to diet and food management may arise in the Senegalese context, such as the perspective of different diets or eating separately from the communal family plate. This may create feelings of social isolation. If reducing servings of traditional foods may make people feel like abandoning culture, ${ }^{55}$ the approach of kitchen toxicology may fit the purpose. ${ }^{8}$ In addition, the health target of good practices against preventable toxicological risk factors is not limited to mother-child health flow. Puberty, menopause and ag- ing represent further windows of enhanced susceptibility to acute, or chronic exposure to toxicants. In fact, in general, age entrains a growing body burden of toxicants, which may worsen the risk and/or the severity of adult diseases. Also diseased subjects are target of secondary prevention strategies mitigating exposure to toxicants. ${ }^{8}$ When behaviors of citizens are difficult to change, such as geophagy (consumption of earthy matters such as clays or chalk), awareness of lost basis of cultural behaviours rooted in traditional medicine or culture may help anthropological work for diseases prevention. ${ }^{16}$

The system stimulation during this field qualitative research highlighted useful aspects in social relations that influence which hazards the community chooses to focus and seeks to counteract, and how they choose to do this. The understanding of community dynamics and ways to circulate information is central. For instance, the social network and way of life make the "word of mouth" a very efficient mode of circulation of information at the community level in Senegal.

Women are responsible of preparing food in Senegal. They have a key role in the economic and cultural development of Senegal as well, and are often protagonist of the Senegalese diaspora (term currently used to indicate displaced people/communities who feel or maintain their connection with the origin country). Women are often organized in associations, such as DEGGOे, ie, the Italian Association of Senegalese Women immigrated in Italy that facilitated the present work, with effective impact on the community. Target population for effective information and communication on mother-child health flow are young women and mothers and more. As acquired on the field, the role of senior women, aunts and grandmothers is also important. Older, experienced women play an influential role in maternal household and child health matters, and this should be taken into account in educational plans. Some educational experiences provide evidence of grandmothers' ability to learn, to integrate new information into their practices and to influence young women's practices positively. ${ }^{56}$ A positive evolution expected from the awarenessspreading process in African societies includes improved and increased men's responsibility in protecting the health and nutrition of their families. Under this respect, the traditional teaching role of grandfathers and uncles might be positively recovered. Educating families on dietary prevention of diseases may be more effective than individual education $^{55}$ having the fact that the whole family eats from the same dish.

All those who have direct contact with mothers and children, eg, educators in schools and nurseries, and health operators that give primary care inputs to mothers like in counselling points and hospitals, should be also be targeted.

In particular, as effect of the system stimulation with key seminal messages given in counselling centers, groups of citizens, and association of women during fieldwork, the proactiveness of the Senegalese association of midwives (Association Nationale des Sages-Femmes d'État du Sénégal, ANSFES) spontaneously emerged. Senegalese midwives learned via word of mouth about such key messages, and tracked me down to know more. During the first meeting 
they reported an unexpected and rapid increase of infertility and breast cancer cases in Senegal. Knowledge of causes of certain cancers turned out as low. Noteworthy, formal presence or absence of diseases "depends" on the community ability to diagnostic, report and collect cases in organized archives. As "sentinel" health workers, midwives can tell in a sensitive and time-effective way on the emerging burden of diseases. ${ }^{57}$ Lay health care figures like midwives have consolidated competence on incidence trends of, eg, infertility, congenital malformations and advanced cancers in the territory. Midwives are multi-skilled key operators and reference figures who serve in preventive as well as in curative medicine (family planning, paediatrics, diet counselling, treatment of infectious and parasitic diseases, gynaecology, detection of sterility, genital and mammary cancers, and sexually transmissible diseases), in both urban and rural settings at capillary level even in remote areas ${ }^{58}$ and, even without knowing the underlying causes, they understand when something new is occurring in the population. In particular, with its network of midwives (650 in 2009, 3000 in 2019) working in villages, town and cities, ANSFES reaches people in all the Senegalese territory, and periodically and frequently meet in plenary in Dakar.

Traditional healers' knowledge and the holistic value of traditional/ethno medicines should be exploited as well, 59 including the traditional religious groups. SFS should be recognised by Koranic study centres and Mouridism.

Along with cultural enablers, possible cultural barriers were investigated. Estimated literacy (defined as the ability to read and write at a specified age) of Senegalese population (age 15 and over) are around 52\% (male: 65\%, female: $40 \%$ ). Therefore, Senegalese population's literacy cannot be taken out of consideration by the information and communication activities. Since 2004, Senegal is administratively divided into 14 regions inhabited by different ethnic groups: Wolof and Lébou (45\%), Pular (25\%), the Serer (14\%) and other less representative groups (Manding, Socé, Soninké). French is the official language and the several ethnic groups have their own language, but most speak Wolof. The native language, Wolof, has no written tradition, thus information and communication activities resort to the French language with literacy skilled people and illustration cards for literacy unskilled people. A previous study reported no relationship between knowledge and literacy or formal education. ${ }^{47}$ While Senegal continues to lag behind in terms of literacy and gender equality, there has been spectacular growth in mobile technology and the use of mobile phones since 2000. Perspectives for mobile health technologies are high. Periodical update and discussion with local communities (eg, focus groups, town meetings) will support effectiveness of awareness and empowerment for health promotion and diseases prevention. Interactions with Senegalese school systems were limited to few days in primary schools and kindergarten during the research, but preliminary impressions of full availability have been corroborated by successive experiences in central-west Africa (Cameroon, Chad) where capacity building within the school system proved to be feasible. University is a growing channel for science-society dialogue as well, ${ }^{14}$ while local weekly press and radio can implement the general health awareness by reaching one-pot a large number of people. ${ }^{60}$

\section{DISCUSSION}

Food systems and diet preferences are dynamic by nature, but they should not be overturned too quickly. Nutrition programmes are increasing in Senegal and in Africa to face the different forms of malnutrition. Based on local diet and foods, dietary recommendations should increase the uptake of protective dietary factors such as folates, antioxidants, essential trace elements (eg, selenium, iodine). Dietary supplements are valuable tools, under medical prescription (eg, excess of essential nutrients may adversely affect developing programming), when a proven deficiency is associated to a correct diet based on the consumption of local food, or in case of (numerous) rare metabolic diseases. Education on the benefits of consuming vegetables and fruit may have a great impact on NCDs prevention. Many programmes in Africa work to diversify food productions and increase the access to diversify micro- (vitamins, trace elements) and macro- (eg, proteins, lipids) nutrients for nutrition security. For instance, the intake of calcium (eg, with dark green vegetables and bones of small sardines or anchovies) and vitamin $\mathrm{D}_{3}$ should be diversified (eg, from sea fish oil), and cereal-based foods should be kept less refined, fractionated, and without recombination with added salt, sugars, and fats. ${ }^{61}$ Some pioneering projects (www.noodlesonlus.org) are working on the prevention of exposure to toxicants that are implicated in malnutrition (both undernutrition and obesity), especially during the development from womb to childhood. ${ }^{19}$ Indeed, many nutritional imbalances and deficiencies are associated with environmental and behavioral factors that are manageable by easy and applicable instructions. Food security, diet, nutrition security, and food safety are inextricably linked, particularly in places where food supplies are insecure (Figure 2). Based on local eating, nutrition security requires efforts in risk analysis to define and promote good practices in food safety at the level of production, ${ }^{52,62,63}$, food consumption, ${ }^{8,53}$ and reporting. 64

Scientific knowledge on the fate of toxicants can be translated in good practices. For instance, persistent organic contaminants, such as dioxins and PCBs, have lipophilic properties and accumulate in adipose animal tissues and oily fish. Age and body size entrain a growing body burden of such accumulating toxicants; trophic position also matters and biomagnification of toxicants occurs in predators. For instance, among foods of animal origin fish has major nutritional benefits and offers aspects of risk prevention (eg, selection of lower size and non-predator species) that are easily manageable by the general consumer. ${ }^{65}$ Other good practices during food handling and cooking (at household, street market, street vended food, or street restaurant level) have been translated from scientific literature. 8,53 Poor storage may cause, eg, contamination by mycotoxins of grains, coffee and cocoa. Smoking, grilling or frying processes can generate highly carcinogenic substances such as polycyclic aromatic hydrocarbons and acrylamide, whereas improper utensils, crockery and food containers can leach metals. Not to neglect the excessive or wrong use of detergents and disinfectants possibly laying down on food.

Good practices for the appropriate selection and safe- 


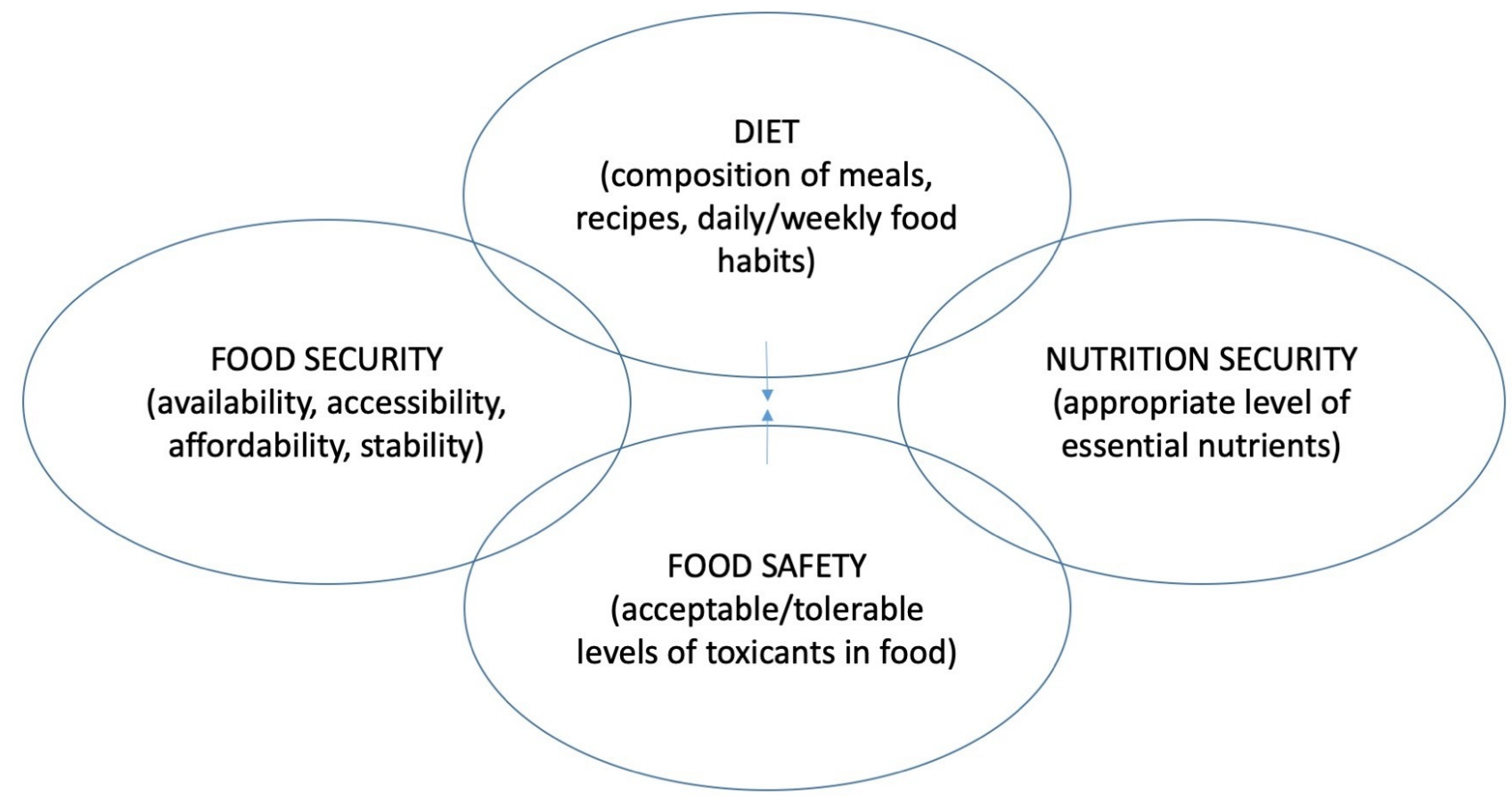

Figure 2. Awareness and empowerment can fill the gap between diet and food safety, and mitigate health risk factors.

guard of the agro-zootechnical environment (eg, pastures) or vending points (eg, markets) may range from eg, distance from industrial sites (with expectedly high dioxin and heavy metals contamination levels) and high vehicular density areas (particulate contamination). Good practices in both selection and handling of feeds for food producing animals are crucial: for instance, cattle fed aflatoxin M1 contaminated feeds produce contaminated milk that is consumed by children or (via the mother consuming milk) breastfed infants. ${ }^{4}$ Science of risk analysis in the sub-Saharan African scenario can prevent environmental exposures and promote clean food chains "from farm to fork" ${ }^{66-68}$ in terms of toxicants, including contaminants (eg, mycotoxins, heavy metals ${ }^{66,69,70}$ ) and residues of agro-zootechnical products, ${ }^{71}$ and antinutritional factors. ${ }^{54}$

The global (formal and informal) market requires global ethics especially towards those countries where rapid changes of lifestyle and consumer preferences, eg, in packaging, cosmetics, clothing, materials (along with lack of awareness and governance, immature or non-existent legislation and infrastructures) make citizens and their environment more at risk. For instance, the market of replacement foods and breastmilk substitutes should be severely surveyed to monitor the compliance with the World Health Organization (WHO) International Code of Marketing of Breastmilk Substitutes. Noticeably, traditional nutraceuticals proven to represent a risk for consumers (eg, geophagic clays) should not be sold amongst food items nor labeled with health claims. ${ }^{16}$ Attention should rise on local food contact materials, eg, the widespread cooking pots in aluminium or tinned copper, and dumped hazardous food contact products such as Bisphenol A baby bottles. ${ }^{52}$ Ad- vocacy is required to recover ethics in global market of unsafe products, as well as in the traffic of hazardous products (eg, e-waste). Increased consumer awareness will also shield from rapid change of preferences and perception of products due to mass media marketing communication (such as the belief that traditional herb tea must be consumed with refined white sugar).

The WHO states that the protection, promotion and support of breastfeeding rank among the most effective interventions to improve child survival. International public health policy recommends exclusive breastfeeding for 6 months, followed by continued breastfeeding with the addition of safe and adequate complementary foods for 2 years and beyond. To avoid undermining the confidence in breastmilk as the optimal food for infants and young children, caution should be exercised when presenting reccomendation to minimize toxicants in breastmilk. Noteworthy, messages about toxicants in breastmilk can become dramatized by the media, impair perception and cause early termination of breastfeeding. ${ }^{72-74}$ The appearance of malnutrition frequently coincides with weaning. ${ }^{75}$ Infant mortality, which is more widespread among children who are not breastfed, is a major cause of a short inter-birth interval. Breastfeeding influences fertility by extending the interval between births. The death of a child at a very young age has the same effect on fecundity as early weaning. National family planning programs (eg, those run by ANSFES) should integrate toxicological risks and give careful attention to breastfeeding as well as to nutrition and toxic body burden of women at least since childbearing age.

Attention should be also pointed at possible undue introduction of foreign food production chains. Ettore Tibaldi 
(2006) supposes that the "original sin" in Africa may have been the introduction of cattle to whom, over time, much land has been allocated for grazing: in environmental conditions of scarcity of water, a bovine needs about 50 litres water per day and consumes cereals in competition with humans. Reasons for absence of certain food products and productions in a territory should be deeply understood. For instance, the limited cheese technology should not a priori evoke poverty, lack of knowledge and tools but could imply, eg, absence of biological utility. In light of this, eg, projects attempting to introduce new cheese technologies become less significant that those pointing at strengthening and disseminating the existing ones (eg, liquid yogurt), and at supporting their local accessibility and export potential. Indeed, a main challenge is the promotion of food sovereignty by healthiness of traditional diet and safety of local food production chains. ${ }^{76,77}$

When contacted for empowerment and awareness on toxicological risk factors, communities in Senegal confirm the proactiveness already shown towards the understanding of dietary and lifestyle risk factors (eg, increased salt, meat, fat, sugar in the diet, smoking, alcohol, decreased physical activity, stress) and associated dysfunctions and long-term diseases. ${ }^{47,78,79}$

Apart from the participation of the celebration "Grand Magal de Touba”, unfortunately this study had no significant contacts with religious leaders of Mouridism. Another limitation is the deficient direct contacts with traditional healers. Both the holistic health approach of ethno medicine and the weight of spiritual evolution both as individual and collective consciousness are aspects of extraordinary importance in sustainable development.

Overall, external efforts for socio-economic development planning in Africa may have been unsuccessful so far because both pastoral cultural roots and pastoral systems have been poorly understood. ${ }^{29}$ The assumptions on pastoral production systems as "inert", "backward" and economically "unreasonable" need to be deeply reconsidered in a framework where labour is cheap, capital is scarce, infrastructures (including transport) are poorly developed, and "development" is not always "progress". This is particularly important given the rapidly changing pastoral productions (from subsistence to commercial), increasing population load and growing per capita needs. This changing scenario is associated with significant environmental problems, from natural environmental degradation and desertification to drought, accompanied by increasing pasture and water scarcity. The subsequent high risk of poor health can be faced if current social, economic and political context of production, that aims more at food security rather than at maximising profits are fully understood. The context is rooted in the individual/community/animals/environment web of interactions, as well as in the balance between civilization and progress, where the true identification of what is "poverty" and what is "system of values" or "best adaptation to the environment" should be understood deeper. Interestingly, economically developed countries are now recovering the "one health" framework, impling interdisciplinarity among human, veterinary and environmental sciences, and intersectorality among science, food business and (human, animal, environmental) health services. ${ }^{80}$ It would not be surprising if economically developed countries will learn from African pastoral culture to recover sustainable view of progress and life.

\section{CONCLUSION}

Public awareness and attitudes towards protective habits, especially in the mother-child health flow, is urgent in population undergoing sweeping socio-economic changes and rapid shift towards an older and more urbanized population. With local efforts to recover an African strong rooted culture and integration, African communities can exploit the experience gathered by economically developed countries to prevent long-term health consequences of the worldwide dominant economic model, such as the burden of NCDs and their comorbidities. When primordial and primary prevention are introduced sooner, they will avoid increasing disadvantages and resistances due to the shortterm loss of development benefits.

In the fast changing scenarios of nutrition transitioning Africa, a key driver that public health actors should pivot on is the new population survival strategy. Indeed, the mechanisms underlying the developmental origin of health and diseases at individual level correspond to a new strategy at population level that requires a decrease in childbirth and aspiration to next generation's better health and healthy life expectancy. This biocultural adaptation offers Africa the framework for focusing on the prevention of new (transgenerational) health risk factors and recovering local food chains and culture, and requires global ethics and advocacy in the global formal and informal markets.

Acknowledgements: This paper has been elaborated in the frame of the "narrative prevention" activities of the ISS in collaboration with the African NGO NOODLES (Nutrition \& food safety and wholesomeness. Prevention, education and research Network, www.noodlesonlus.org). The Senegalese Association of Midwifes, ANSFES, is acknowledged for its proactive collaboration on the Senegalese territory. In particular, my acknowledgements go to Ms. Marième Fall and Ms. Aissatou Diop. I also thank the friendly sustain received from the Italian Association of Senegalese Women immigrated in Italy DEGGÒ and, in particular, of Ms. Thiama Mbow in the Mbacke region and Ms. Ndeye Djeynaba Tine in the Dakar Region. I'm grateful to Dr. Fatou Corka Kan, executive secretary of the National Council of Food Security, Dakar, Senegal, for her professional perusal of the paper.

Competing interests: The author has completed the ICMJE form (available upon request from the corresponding author), and declares no conflict of interest.

\section{Authorship contribution: $\mathrm{CF}$ is the sole author.}

\section{Correspondence to:}

Chiara Frazzoli

Department of Cardiovascular and Endocrine-Metabolic Diseases, and Ageing, 
Istituto Superiore di Sanità,

Rome, Italy.

chiara.frazzoli@iss.it

This is an open-access article distributed under the terms of the Creative Commons Attribution 4.0 International License (CCBY-4.0). View this license's legal deed at http://creativecommons.org/licenses/by/4.0 and legal code at http://creativecommons.org/licenses/by/4.0/legalcode for more information. 


\section{REFERENCES}

1. Gouda HN, Charlson F, Sorsdahl K, et al. Burden of non-communicable diseases in sub-Saharan Africa, 1990-2017: Results from the Global Burden of Disease Study 2017. The Lancet Global Health. 2019;7(10):e1375-e1387. doi:10.1016/s2214-109x(1 9)30374-2

2. Bosu WK. An overview of the nutrition transition in West Africa: Implications for non-communicable diseases. Proc Nutr Soc. 2015;74:466-477. doi:10.101 7/S0029665114001669

3. Orisakwe OE, Frazzoli C, Ilo CE, Oritsemuelebi BA. The public health burden of e-waste in Africa. $J$ Health Pollution. 2019;9:22. doi:10.5696/2156-961 $\underline{4-9.22 .190610}$

4. Frazzoli C, Orisakwe OE, Dragone R, Mantovani A. Diagnostic health risk assessment of electronic waste on the general population in developing countries' scenarios. Environ Impact Assess Rev. 2010;30:388-399. doi:10.1016/i.eiar.2009.12.004

5. Frazzoli C, Petrini C, Mantovani A. Sustainable development and next generation's health: A longterm perspective about the consequences of today's activities for food safety. Ann Ist Sup Sanità. 2009;45:65-75.

6. Wenjun Z, Fubin J, JiangFeng O. Global pesticide consumption and pollution: With China as a focus. Int Acad Ecol Environ Sci. 2011;1:125-144.

7. Xiaohui X, Hui H, Yan Alicia H. Body burden of heavy metals among HIV high risk population in USA. Environmental Pollution. 2017;220:1121-1126. doi:1 $\underline{0.1016 / j . e n v p o l .2016 .11 .023}$

8. Frazzoli C, Mazzanti F, Achu MB, Pouokam GB, Fokou E. Elements of kitchen toxicology to exploit the value of traditional (African) recipes in the diet of HIV+/AIDS subjects: The case of Egusi okra meal. Toxicology Reports. 2017;4:474-483.

9. Wagachaa JM, Muthomib JW. Mycotoxin problem in Africa: Current status, implications to food safety and health and possible management strategies. Int $J$ Food Microbiology. 2008;124,1,10,1-12. doi:10.1016/ j.ijfoodmicro.2008.01.008

10. Heindel JJ, vom Saal FS, Blumberg B, Bovolin P, Calamandrei G, Ceresini G, et al. Parma consensus statement on metabolic disruptor. Environ Health. 2015:14-54. doi:10.1186/s12940-015-0042-7
11. Pullar J, Wickramasinghe K, Demaio AR, Roberts N, Perez-Blanco KM, Noonan K, et al. The impact of maternal nutrition on offspring's risk of noncommunicable diseases in adulthood: A systematic review. J Glob Health. 2019;9:020405. doi:10.7189/jog h.09.020405

12. United Nations. Our Common Future: Report of the World Commission on Environment \& Development. Brundtland Report. 1987.

13. Frazzoli C, Mantovani A. Combining a bottom-up movement: Endocrine disruptors and noncommunicable diseases in Africa. Open Access Government edition. 2019;23.

14. Orisakwe OE, Asongalem EA, Frazzoli C. Scientific research in veterinary public health as driver for development. In: Frazzoli C, Asongalem EA, Orisakwe OE, eds. Cameroon-Nigeria-Italy Scientific Cooperation: Veterinary Public Health and Sustainable Food Safety to Promote "One Health/One Prevention.”; 2012:vi, 198.

15. Modonesi C, Oddone E, Panizza C, Imbriani M. The missing link between human ecology and public health: The case of cancer. G Ital Med Lav Ergon. 2017;39:106-112.

16. Frazzoli C, Pouokam GB, Mantovani A, Orisakwe OE. Health risks from lost awareness of cultural behaviours rooted in traditional medicine: An insight in geophagy and mineral intake. Sci Tot Environment. 2016;566-567:1465-147. doi:10.1016/i.scitotenv.201 $\underline{6.06 .028}$

17. Mantovani A. Characterization and Management of Uncertainties in Toxicological Risk Assessment: Examples from the Opinions of the European Food Safety Authority. Methods Mol Biol. 2018;1800:219-229. doi:10.1007/978-1-4939-789 9-1_10

18. Cohen E, Gradidge PJ, Ndao A, Duboz P, Macia E, Gueye L, et al. Biocultural determinants of overweight and obesity in the context of nutrition transition in Senegal: A holistic anthropological approach. J Biosoc Sci. 2019;51:469-490. doi:10.1017/S002193201800028 $\underline{7}$

19. Kampman H, Zongrone A, Rawat R, Becquey E. How Senegal created an enabling environment for nutrition: A story of change. Global Food Security. 2017;13:57-65. doi:10.1016/j.gfs.2017.02.005 
20. Abrahams Z, McHiza Z, Steyn NP. Diet and mortality rates in Sub-Saharan Africa: Stages in the nutrition transition. BMC Public Health. 2011;11:801. doi:10.1186/1471-2458-11-801

21. Mahajan V. Africa Rising. Upper Saddle River, New Jersey 07458: Wharton School Publishing; 2009.

22. Anderson CAM, Bellamy S, Figures M, ZeiglerJohnson C, Jalloh M, Spangler E, et al. Dietary intake of Senegalese adults. Nutr J. 2010;9:7. doi:10.1186/14 75-2891-9-7

23. EFSA ANS Panel. Scientific Opinion on thereevaluation of glutamic acid (E 620), sodium glutamate (E 621), potassium glutamate (E 622), calcium glutamate (E 623), ammonium glutamate (E 624) and magnesium glutamate (E 625) as food additives. EFSA Journal. 2017;15:4910.

24. Issaka AI, Agho KE, Page AN, Burns PL, Stevens GJ, Dibley MJ. Factors associated with early introduction of formula and/or solid, semi-solid or soft foods in seven Francophone West African countries. Nutrients. 2015;30;7:948-969. doi:10.3390/ $\underline{\text { nu7020948 }}$

25. Agne-Djigo A, Kwadjode KM, Idohou-Dossou N, Diouf A, Guiro AT, Wade S. Energy intake from human milk covers the requirement of 6-month-old Senegalese exclusively breast-fed infants. Br J Nutr. 2013;110(10):1849-1855. doi:10.1017/s000711451300 $\underline{1074}$

26. Issaka AI, Agho KE, Page AN, L. Burns P, Stevens GJ, Dibley MJ. Determinants of suboptimal complementary feeding practices among children aged 6-23 months in seven francophone West African countries. Matern Child Nutr. 2015;11:31-52. doi:10.1 111/mcn.12193

27. Gupta N, Gehri M, Stettler N. Early introduction of water and complementary feeding and nutritional status of children in northern Senegal. Public Health Nutr. 2007;10:1299-1304. doi:10.1017/S13689800076 $\underline{96384}$

28. Simondon KB, Simondon F. Infant feeding and nutritional status: The dilemma of mothers in rural Senegal. Eur J Clin Nutr. 1995;49:179-188.

29. Benefice E, Chevassus - Agnes S, Barral H. Nutritional situation and seasonal variations for pastoralist populations of the sahel (Senegalese Ferlo). Ecology of Food and Nutrition. 1984;14(3):229-247. doi:10.1080/03670244.1984.9990 $\underline{790}$

30. Adriansen HK. Continuity and Change in Pastoral Livelihoods of Senegalese Fulani. Agric Hum Values. 2006;23(2):215-229. doi:10.1007/s10460-005-6108-3
31. Meir A. Comparative vital statistics along the pastoral nomadism-sedentarism continuum. Hum Ecol. 1987;15:91-107. doi:10.1007/BF00891373

32. Simoons FJ. The geographic hypothesis and lactose malabsorption. A weighing of the evidence. Am J Dig Dis. 1978;23:963-980.

33. Simoons FJ. Primary adult lactose intolerance and the milking habit: A problem in biological and cultural interrelations. II A culture historical hypothesis Am J Digest Dis. 1970;15:695-710. doi:1 $\underline{0.1007 / B F 02235991}$

34. Dyson-Hudson R, Dyson-Hudson N. Nomadic Pastoralism. Ann Rev Anthropol. 1980;9:15-61.

35. Arnold J, Diop M, Kodjovi M, Rozier J. Lactose intolerance in adults in Senegal. C R Seances Soc Biol Fil. 1980;174:983-992.

36. Mantovani A. Mediterranean and zoonoses: A long lasting association. Giornale Italiano di Medicina Tropicale. 2006;11:57-64.

37. Flatz G. Genetics of lactose digestion in humans. Adv Hum Genet. 1987;16:1-77. doi:10.1007/978-1-47 57-0620-8 1

38. Tibaldi E. Cibo d'Africa. Percorsi alimentari dal Sahara a Soweto. (Slow Food, ed.).; 2006.

39. Crenn C, Delavigne AE, Techoueyres I. Migrants' food habits when returning home (in Bamako, Mali, and Dakar, Senegal) to be or not to be a model? Anthropology of Food. 2010;7:6629.

40. Berrino F. Prevention and TAO. Epidemiol Prev. 2010;34:83-86.

41. Alles M, Eussen S, Ake-Tano O, Diouf S, Tanya A, Lakati A, et al. Situational analysis and expert evaluation of the nutrition and health status of infants and young children in five countries in subSaharan Africa. Food Nutr Bull. 2013;34:287-298. do i:10.1177/156482651303400301

42. Powell DA, Jacob CJ, Chapman B. Enhancing food safety culture to reduce rates of foodborne illness. Food Control. 2011;22:817-822. doi:10.1016/j.foodcon t.2010.12.009

43. Ronsmans C. Birth spacing and child survival in rural Senegal. Int J Epidemiol. 1996;25:989-997. doi:1 $\underline{0.1093 / \mathrm{ije} / 25.5 .989}$

44. Goldberg HI, M’Bodji FG, Friedman JS. Fertility and family planning in one region of Senegal. Int Fam Plann Persp. 1986;12:116-122. doi:10.2307/2947982 
45. National Research Council. Population Dynamics of Senegal. Washington, DC: The National Academies Press; 1995.

46. Frazzoli C. Trade not aid: Challenges for market drivers of safe foods in Africa. In: Cameroon-NigeriaItaly scientific cooperation: veterinary public health and sustainable food safety to promote "one health/ one prevention.” In: Frazzoli C, Asongalem EA, Orisakwe OE, eds. Rome: Rapporti ISTISAN; 2012:60-69.

47. Holdsworth M, Delpeuch F, Landais E, Gartner A, Eymard-Duvernay S, Maire B. Knowledge of dietary and behaviour-related determinants of noncommunicable disease in urban Senegalese women. Public Health Nutr. 2006;9:975-981. doi:10.1017/PHN $\underline{2006979}$

48. Rickard IJ, Holopainen J, Helama S, Helle S, Russell AF, Lummaa V. Food availability at birth limited reproductive success in historical humans. Ecology. 2010;91:3515-3525. doi:10.1890/10-0019.1

49. Dietert RR. Developmental immunotoxicity, perinatal programming, and non-communicable diseases: Focus on human studies. Adv Med. 2014;867805. doi:10.1155/2014/867805

50. Wells JCK. The thrifty phenotype as an adaptive maternal effect. Biol Rev. 2007;82:143-172. doi:10.11 11/i.1469-185X.2006.00007.X

51. Bateson P, Barke D, Clutton-Brock T, Deb D, D’Udine B, Foley RA, et al. Developmental plasticity and human health. Nature. 2004;430:419-421. doi:1 $0.1038 /$ nature 02725

52. Pouokam GB, Ajaezi GC, Mantovani A, Orisakwe OE, Frazzoli C. Use of Bisphenol A-containing baby bottles in Cameroon and Nigeria and possible risk management and mitigation measures: Community as milestone for prevention. Sci Total Environ. 2014;481:296-302. doi:10.1016/j.scitotenv.2014.02.02 $\underline{6}$

53. Proietti I, Frazzoli C, Mantovani A. Identification and management of toxicological hazards of street foods in developing countries. Food Chem Toxicol. 2014;63:143-152. doi:10.1016/j.fct.2013.10.047

54. Proietti I, Frazzoli C, Mantovani A. Exploiting nutritional value of staple foods in world's semi-arid areas: Risks and benefits, challenges and opportunities of sorghum. Healthcare. 2015;3:172-193. doi:10.3390/healthcare3020172

55. Foley E, BeLue R. Identifying barriers and enablers in the dietary management of type 2 diabetes in M'Bour, Senegal. J Transcult Nurs. 2017;28:348-352. doi:10.1177/1043659616649028
56. Aubel J, Touré I, Diagne M. Senegalese grandmothers promote improved maternal and child nutrition practices: The guardians of tradition are not averse to change. Soc Sci Med. 2004;59:945-959. doi:1 0.1016/j.socscimed.2003.11.044

57. Dyjack D, Soret S, Chen L, Hwang R, Nazari N, Gaede D. Residential environmental risks for reproductive age women in developing countries. $J$ Midwifery Womens Health. 2005;50:309-314. doi:10.1 016/i.jmwh.2005.02.001

58. Ndiaye DF. Training of the midwife in Senegal. Journal of family health training J Famil Health Train. 1982;1:3-5.

59. Kofi-Tsekpo M. Institutionalization of African traditional medicine in health care systems in Africa. Afr J Health Sci. 2004;11:1-2.

60. Semakula D, Nsangi A, Oxman M, Rosenbaum SE, Oxman AD, Austvoll-Dahlgren A, et al. Development of mass media resources to improve the ability of parents of primary school children in Uganda to assess the trustworthiness of claims about the effects of treatments: A human-centred design approach. Pilot Feasibility Stud. 2019;5:155. doi:10.1186/s4081 4-019-0540-4

61. Fardet A, Rock E, Bassama J, Prabhasankar P, Monteiro C, Moubarac JC, et al. Current food classification in epidemiological studies do not enable solid nutritional recommendations for preventing diet-related chronic diseases: The impact of food processing. Adv Nutr. 2015;6:629-638. doi:1 $\underline{0.3945 / a n .115 .008789}$

62. Frazzoli C, Mantovani A. Toxicants exposures as novel zoonoses: Reflections on sustainable development, food safety and veterinary public health. Zoonoses and Public Health. 2010;57(7-8):e136-e142. doi:10.1111/j.1863-2378.200 9.01309.x

63. Mmualefe LC, Torto N. Environmental and food sample handling challenges for developing countries. Toxicol environ chem. 2009;91:819-835. doi:10.1080/ 02772240802674592

64. Bertrand P, Ahmed H, Ngwafor R, Frazzoli C. Toxicovigilance systems and practices in Africa. Toxics. 2016;4(3):13. doi:10.3390/toxics4030013

65. Mantovani A, Ferrari D, Frazzoli C. Sustainability, security and safety in the feed-to-fish chain: Focus on toxic contamination. Int Journal Nutrition and Food Sciences. 2015;4(2-2):6-24. doi:10.11648/i.ijnfs.s.201 $\underline{5040202.12}$ 
66. Frazzoli C, Bocca B, Mantovani A. The one health perspective in trace elements biomonitoring. $J$ Toxicol Environ Health B Crit Rev. 2015;18:344-370. doi:10.1 080/10937404.2015.1085473

67. Cheng R, Mantovani A, Frazzoli C. Analysis of food safety and security challenges in emerging African food producing areas through a One Health lens: The dairy chains in Mali. J Food Prot. 2017;80,1,57-67.

68. Pouokam GB, Foudjo BUS, Samuel C, et al. Contaminants in Foods of Animal Origin in Cameroon: A One Health Vision for Risk Management "from Farm to Fork." Front Public Health. 2017;5. do i:10.3389/fpubh.2017.00197

69. Frazzoli C, Gherardi P, Saxena N, Belluzzi G, Mantovani A. The hotspot for (global) one health in primary food production: Aflatoxin M1 in dairy products. Front Public health. 2017;4:294. doi:10.338 9/fpubh.2016.00294

70. Ladeira C, Frazzoli C, Orisakwe OE. Engaging One Health for non-communicable diseases in Africa: Perspective for mycotoxins. Front Public health. 2017;5:266. doi:10.3389/fpubh.2017.00266

71. Mantovani A, Frazzoli C. Risk assessment of toxic contaminants in animal feed. CAB Reviews:

Perspectives in Agriculture, Veterinary Science, Nutrition and Natural Resources. 2010;5,046:1. doi:1 0.1079/PAVSNNR20105046

72. Arendt M. Communicating human biomonitoring results to ensure policy coherence with public health recommendations: Analysing breastmilk whilst protecting, promoting and supporting breastfeeding. Environmental Health. 2008;7(Suppl 1):S6. doi:10.11 86/1476-069x-7-s1-s6
73. Altman RG, Morello-Frosch R, Brody JG, Rudel R, Brown P, Averick M. Pollution comes home and gets personal: Women's experience of household chemical exposure. J Health Soc Behav. 2008;49:417-435. doi:1 0.1177/002214650804900404

74. Geraghty SR, Khoury JC, Morrow AL, Lanphear BP. Reporting individual test results of environmental chemicals in breastmilk: Potential for premature weaning. Breastfeed Med. 2008;3:207-213. doi:10.108 9/bfm.2008.0120

75. Mondot-Bernard J. Fertility and breast-feeding in Africa. Afr Environ. 1981;(14-16):131-150.

76. Gibson RS, Anderson VP. A review of interventions based on dietary diversification or modification strategies with the potential to enhance intakes of total and absorbable zinc. Food Nutr Bull. 2009;30:S108-143. doi:10.1177/15648265090301S107

77. Delpeuch F, Martin-Prével Y, Fouéré T, Traissac P, Mbemba F, Ly C, et al. Complementary nutrition for the young child following the devaluation of the CFA franc (African Financial Community): 2 case studies in the Congo and Senegal urban environment. Bull World Health Organ. 1996;74:67-75.

78. Sodjinou R, Agueh V, Fayomi B, Delisle H. Obesity and cardio-metabolic risk factors in urban adults of Benin: Relationship with socio-economic status, urbanisation, and lifestyle patterns. BMC Public Health. 2008;8:84-96. doi:10.1186/1471-2458-8-84

79. Gning SB, Thiam M, Fall F, Ba-Fall K, Mbaye PS, Fourcade L. Diabetes mellitus in sub-Saharan Africa: Epidemiological aspects and management issues. Med Trop (Mars). 2007;67:607-611.

80. Frazzoli C, Mantovani A. Editorial: The environment-animal-human web: A "One Health" view of toxicological risk analysis. Front Public Health. 2018;6:353. doi:10.3389/fpubh.2018.00353 